\title{
UN SCRIPTORIUM DEL SIGLO XIII EN EL MONASTERIO CISTERCIENSE DE LA SANTA ESPINA (VALLADOLID)
}

\section{A $13^{\text {th }}$ CENTURY SCRIPTORIUM IN THE CISTERCIAN MONASTERY OF LA SANTA ESPINA (VALLADOLID)}

\author{
Rafael Cómez Ramos \\ Universidad de Sevilla. España \\ rcomez@us.es
}

\begin{abstract}
En este artículo se establece la hipótesis de un scriptorium del siglo XIII en el monasterio cisterciense de la Santa Espina (Valladolid) donde habría sido iluminado el fragmento 4852 (Archivo General de la Nación, México).

Palabras clave: manuscritos iluminados; Beatos; miniatura castellana del siglo XIII; scriptoria cistercienses; monasterios cistercienses en Castilla.
\end{abstract}

This paper establishes the hypothesis of a $13^{\text {th }}$ century scriptorium in the Cistercian Monastery of La Santa Espina (Valladolid) where the fragment 4852 (Archivo General de la Nación, México) would have been illuminated.

Keywords: illuminated manuscripts; Beatos; $13^{\text {th }}$ century Castilian miniature; Cistercians scriptoria; Cistercians monasteries in Castile.

El descubrimiento de un fragmento de uno de los últimos Beatos conocidos en el Archivo General de la Nación de la ciudad de México en 1985 nos llevó a interesarnos, de una parte, por la historia de los manuscritos mutilados y perdidos, y de otra, por el lugar de donde procediera nuestro hallazgo, ya que sus interesantes miniaturas representaban uno de los últimos eslabones de la larga tradición pictórica de los Beatos mozárabes, siendo exhibido en la exposición "Los 
Beatos" de la Biblioteca Real de Bruselas ${ }^{1}$, catalogado ${ }^{2}$ y dado a conocer en el Coloquio "Los Beatos", celebrado dentro del marco de "Europalia 85 España"3, conociendo su publicación poco después en México por el Archivo General de la Nación ${ }^{4}$. Ahora bien, hasta hace poco no habíamos podido tener suficientes elementos de juicio para establecer una hipótesis sobre el scriptorium del que procediera el códice cuyas interesantes miniaturas significan la última representación del tema apocalíptico en versión gótica. Así pues, nuestro propósito consiste en establecer una relación entre el fragmento mexicano y su posible lugar de procedencia. Para ello, trataremos primero acerca del mencionado fragmento, y segundo, presentaremos nuestra hipótesis acerca del posible scriptorium en donde se iluminara y se copiara el correspondiente códice.

La curiosa historia de los manuscritos perdidos, mutilados y reutilizados como soporte o también como encuadernación abunda en infinidad de variados ejemplos pero quizá ninguno tan especial y de largo recorrido como el que nos ocupa en estas páginas. Bien sabido es que en la Edad Media no era extraño que fueran reutilizados los pergaminos ante la escasez de materiales para la escritura, constituyendo los llamados palimpsestos. Sin embargo, al llegar los tiempos modernos los pergaminos medievales fueron también reutilizados, en este caso, como estupendas cubiertas de libros. Famosos manuscritos iluminados con preciosas miniaturas corrieron esa suerte, tal el Quedlinburg Itala, de la Deutsche Staatsbibliothek de Berlín, cuyos seis folios con ilustraciones del Libro de los Reyes fueron utilizados para encuadernación por Asmus Reitel de Quedlinburg en 1618 y descubiertos, más tarde, en 1865, siendo entregados a la Biblioteca Real ${ }^{5}$.

* Este trabajo de investigación se enmarca dentro de la Red de Excelencia "Ars mediaevalis" (HAR 2015-71667-REDT). El autor agradece al Dr. Fernando Gutiérrez Baños, profesor titular de la Universidad de Valladolid, sus atenciones durante la excursión a los montes Torozos en la cual conocimos el monasterio de la Santa Espina.

${ }^{1}$ Los Beatos. Europalia 85 España, 26 septembre-30 noviembre 1985, Chapelle de Nassau, Bibliothèque royale Albert I, Bruselas.

2 MUNDÓ, Anscari M. y SÁNCHEZ MARIANA, Manuel: "Catalogue", Los Beatos, Europalia 85 España. Bruselas, 1985, nº 18, pp. 116 y 148.

3 CÓMEZ, Rafael: "Un Beato du XIIIème siècle à México", Colloque Los Beatos, Europalia 85 España. Bibliothèque royale Albert I, Bruselas, 1985.

${ }^{4}$ CÓMEZ, Rafael: El documento más antiguo del Archivo General de la Nación (fragmento de un Beato del siglo XIII). México D.F., 1985.

${ }_{5}^{5}$ WEITZMANN, Kurt: Late Antique and Early Christian Book Illumination. Nueva York, 1977, p. 27. En otro contexto véase también COLLIN-ROSET, Simone: "La reliure" y "Livres usés, mutilés, lacérés", en Écriture et enluminure en Lorraine au Moyen Âge, 
A partir de la baja Edad Media, documentos administrativos, actas judiciales y escrituras notariales reutilizaron textos literarios y escolásticos al tiempo que los Reyes Católicos en la Pragmática de 7 de junio de 1503 obligaban a los escribanos públicos a encuadernar las escrituras del protocolo notarial. Esta medida dio pábulo a que en las notarías, audiencias y chancillerías se utilizaran los viejos pergaminos y antiguas escrituras para la encuadernación de los cuadernos de papel, poniendo en la parte exterior un folio o bifolio de pergamino según el tamaño del cuaderno, resultando siempre más deteriorada la antigua escritura de la cara externa del pergamino por el uso y continuo roce mientras quedaba mejor conservada su cara interna como en el caso del folio mexicano que comentaremos más adelante ${ }^{6}$. Esta fue la costumbre hasta los tiempos modernos ya que se sabe que en pleno siglo XVIII, no lejos de Burgos, en la biblioteca del monasterio de San Pedro de Cardeña "los monjes deshojaban muchos códices para haber cartones con que forrar otros libros" " No obstante, otras veces, la perenne calidad del pergamino y su lenta ignición permitió su reutilización para fines menos nobles que la encuadernación tales como el ahumado de embutidos o la fabricación de cartuchos de escopeta.

El folio de pergamino $(490 \times 310 \mathrm{~mm})$ que comentaremos a continuación constituía el folio 25v del volumen 67 del ramo Inquisición, catalogado con el número $4852^{8}$, y sirvió de encuadernación a un expediente de limpieza de sangre solicitado por la Inquisición de México para conocer la genealogía del escribano Gregorio de Quintana, quien deseaba ser familiar del Santo Oficio en las minas de Pánuco en Zacatecas "por no haber otra persona en aquel distrito". En el último folio del mencionado volumen aparece escrito "Árbol genealógico de Gregorio Quintana, interrogatorio y un pergamino en latín", referencia anotada por el archivero que reunió todos los documentos contenidos en dicho volumen ${ }^{9}$. El expediente está fechado en "la noble villa de Medina de Ríoseco a ocho días del mes de febrero año del señor de mil quinientos y cinquenta y nueve años" ${ }^{\text {". }}$. En la

Catalogue de l'exposition La plume et le parchemin, 29 mai-29 juillet 1984, Musée historique lorrain. Nancy, 1984, pp. 9-13.

${ }^{6}$ ROMERO TALLAFIGO, Manuel: De libros, archivos y bibliotecas. Venturas y desventuras de la escritura. Las Palmas de Gran Canaria, 2008, p. 221.

7 MILLARES CARLO, Agustín: Introducción a la historia del libro y las bibliotecas. México, 1971, p. 244.

${ }^{8}$ Catálogo de Ilustraciones. México D.F., Archivo General de la Nación, 1979-1981, 12.

${ }_{9}$ CÓMEZ, Rafael: El documento más antiguo del Archivo General de la Nación, op. cit., p. 2.

${ }^{10}$ CÓMEZ, Rafael: "Un fragmento de un Beato del siglo XIII en México", Archivo Español de Arte, 246, 1989, pp. 209-211; y CÓMEZ RAMOS, Rafael: "Anónimo, Fragmento de un Beato", en Laboratorio de Arte, 100 años de investigación del patrimonio artístico y cultural (1907-2007). Sevilla, 2007, pp. 86-87. 
parte superior del folio aparece cosido un estrecho fragmento mutilado perteneciente al mismo códice y que se adhirió con objeto de ampliar la superficie de la encuadernación. Así pues, este caso queda dentro de los que han sido denominados libros intuidos, libros viajeros y libros $\operatorname{rotos}^{11} \mathrm{y}$, concretamente, en un libro roto con objeto de aprovechar su viejo pergamino para encuadernar unos documentos con absoluto desprecio de texto y miniatura.

La miniatura es de gran sobriedad y de dibujo perfecto, destacando el contorno negro de las figuras y el rojo de la viñeta e iniciales del texto sobre el pergamino, mientras que ocupa aproximadamente algo más de la mitad inferior del folio, bajo las dos columnas del texto. Ningún otro color aparece a excepción de un tenue color amarillo en el libro y en el halo de Cristo; por otra parte, muestran color rojo de fondo dos pequeñas cruces en forma de equis situadas respectivamente en los lados superior e inferior del marco de la miniatura. Pudiera pensarse que la miniatura quedó, pues, en su primera fase de dibujo sin llegar a ser coloreada $^{12}$, sin embargo, no es así puesto que el diseño es acabado en sí, como si no necesitara del color para resultar expresivo, rimando el negro de las figuras con el color de las letras del texto y la ligera nota de color rojo del marco con la última línea del mismo color de la primera columna del texto y con la letra inicial de la segunda columna (Figura 1). Dada su sobriedad y elegancia de dibujo diríase próxima al espíritu cisterciense ${ }^{13}$. Bien conocidas son la fluctuaciones de la miniatura cisterciense desde la primitiva etapa de la Biblia y las Moralia in Job de la Biblioteca Municipal de Dijon ${ }^{14}$ hasta la correspondiente al rigorismo impuesto por la Carta Charitatis (1114) y los Estatutos de Citeaux (1150), cuyo

11 SUÁREZ GONZÁLEZ, Ana Isabel: "El libro en los claustros cistercienses: una aproximación (c. 1140-1240)", en El monacato en los reinos de León y Castilla (siglos VIIXIII). Ávila, 2007, p. 266. Con posterioridad contamos con una espléndida edición, vid. SUÁREZ GONZÁLEZ, Ana Isabel: "Los otros beatos", en Fragmentos de beatos (estudios y edición facsímil). 2 vols. Madrid, 2009. Sobre la importancia de estos fragmentos de pergaminos reutilizados, véase también la introducción y análisis de la magnífica monografía de GALVÁN FRAILE, Fernando: Fragmentos de manuscritos iluminados en el archivo Histórico provincial de León (c. 1200). León, 2000, pp. 15-21 y ss.

12 YARZA LUACES, Joaquín: Beato de Liébana. Manuscritos iluminados. Barcelona, 1998, p. 304.

${ }^{13}$ SURCHAMP, Angelico: "L'esprit de l'art cistercien", en DIMIER, M. Anselme y PORCHER, Jean: L'art cistercien: France. París, 1962, p. 24. Véase también las páginas dedicadas al arte cisterciense por SCHAPIRO, Meyer: "Sobre la actitud estética en el arte románico (1947)”, en Estudios sobre el románico. Madrid, 1984, pp. 17-21.

${ }^{14}$ OURSEL, Charles: La miniature du XIIème siècle à l'Abbaye de Citeaux d'après les manuscrits de la Bibliothèque de Dijon. Dijon, 1927; ZALUSKA, Yolanta: L'enluminure et le scriptorium de Citeaux au XIIème siècle. Abbaye de Citeaux, 1989; y YARZA LUACES, Joaquín: "Manuscritos iluminados en el Císter", en Monjes y monasterios. El Císter en el medievo de Castilla y León. Valladolid, 1998, p. 400. 
artículo 82 prescribía que en los manuscritos "Litterae unius coloris fiant et non depictae", que conllevaba un estilo severo y desnudo que se reducía a las sencillas iniciales, sus proporciones, puro grafismo y mise en page del texto ${ }^{15}$. No obstante, dada la necesidad de los textos para la lectura diaria que imponía la regla, la actividad de los scriptoria fue incesante y aquellas prescripciones no fueron tomadas con demasiado entusiasmo de tal modo que la afición a ilustrar códices no sería nunca completamente reprimida ${ }^{16}$. El estilo es claramente el gótico lineal que se introduce en Castilla y León hasta finales del reinado de Fernando $\mathrm{III}^{17}$, es decir, en otras palabras, el protogótico hispánico ${ }^{18}$, definido por Azcárate, que coincide con el ámbito cronológico del llamado estilo $1200^{19}$, que abarca aproximadamente entre 1170 y 1230, según la propuesta de Grodecki, y que tuvo su reconocimiento a partir de la exposición y simposio organizados en 1970 por el Metropolitan Museum of Art de Nueva York ${ }^{20}$, caracterizándose por la línea firme del contorno, los amplios pliegues y cierto aspecto clasicista de influencia bizantina en una transición del arte románico al gótico, todo lo cual hace aún más interesante la indagación acerca del mutilado folio que muestra la deteriorada miniatura.

${ }^{15}$ PORCHER, Jean: L'enluminure française. París, 1959, p. 40; PORCHER, Jean: "L'enluminure cistercien", en DIMIER, M. Anselme y PORCHER, Jean: L'art cistercien, op. cit., pp. 320, 324 y 329; YARZA LUACES, Joaquín: "Manuscritos iluminados en el Císter", op. cit., p. 400. Los Estatutos y normas arquitectónicas del Capítulo general del Císter respecto a escultura, pintura y vidrieras fueron publicados en el apéndice documental de BRAUNFELS, Wolfgang: La arquitectura monacal en Occidente. Barcelona, 1975, pp. 321 y ss.

16 PORCHER, Jean: "L'enluminure cistercien", op. cit., p. 324; y DUBY, Georges: San Bernardo y el arte cisterciense (el nacimiento del gótico). Madrid, 1981, p. 142.

${ }^{17}$ GUTIÉRREZ BAÑOS, Fernando: Aportación al estudio de la pintura de estilo gótico lineal en Castilla y León: precisiones cronológicas y corpus de pintura mural y sobre tabla. 2 tt. Madrid, 2005. Véase un compendio de esta tesis doctoral en GUTIÉRREZ BAÑOS, Fernando: "La pintura en el territorio burgalés en los siglos XIII y XIV: el desarrollo del estilo gótico lineal”, en RODRÍGUEZ PAJARES, Emilio Jesús: El arte gótico en el territorio burgalés. Burgos, 2006, pp. 273-300.

18 AZCÁRATE, José María: El protogótico hispánico. Madrid, 1974, pp. 65-71.

19 GRODECKI, Louis: "Le Style 1200”, en Le Moyen Âge retrouvé. París, 1986, pp. 385-398. Podríamos considerar dicho estilo 1200 como una fase manierista del arte medieval si tenemos en cuenta los ejemplos (Zackenstil) del Evangeliario de Maguncia en Aschaffenburg, el Psalterio del monasterio de Rheinau en Zürich y el Psalterio cisterciense de la diócesis de Basilea en Besançon, aducidos por WEISBACH, Werner: Manierismus in mittelalterlichen Kunst. Basilea, 1942, p. 30 (Abb. 30-31-32).

${ }^{20}$ HOFFMAN, Konrad: The Year 1200. A Centenial Exhibition at The Metropolitan Museum of Art. Nueva York, 1970; HOFFMAN, Konrad: The Year 1200. A Background Survey. Nueva York, 1970; y AVRIL, François et alii: The Year 1200. A Symposium. Nueva York, 1975. 
El tema iconográfico corresponde a la denominada Primera Resurrección -"Et vidi thronos et sedentes super eos..." (Apocalipsis, 20, 4-6)- según el Index of Christian Art de la Universidad de Princeton, que Neuss denominó Los tronos de los justos y las almas de los mártires ${ }^{21}$, en que aparecen los tronos de los justos y las almas de los mártires en forma de pájaros o palomas, integrado dentro del capítulo titulado El reino de mil años que reza así:

"Luego vi unos tronos, y se sentaron en ellos, y se les dio el poder de juzgar; vi también las almas de los que fueron decapitados por el testimonio de Jesús y la Palabra de Dios, y a todos los que no adoptaron a la Bestia ni a su imagen, y no aceptaron la marca en su frente o en su mano; revivieron y reinaron con Cristo mil años. Es la primera resurrección. Los demás muertos no revivieron hasta que se acabaron los mil años. Dichoso y santo el que participa en la primera resurrección; la segunda muerte no tiene poder sobre éstos, sino que serán Sacerdotes de Dios y de Cristo y reinarán con Él mil años"22.

Por lo que respecta al fragmento mutilado y cosido en la parte superior del folio, se trata del pasaje llamado El primer combate escatológico -"Et vidi angelum..." (Apocalipsis, 19, 17-18)-, que dice así:

"Luego vi a un Ángel de pie sobre el sol que gritaba con fuerte voz a todas las aves que volaban por lo alto del cielo: Venid, reuníos para el gran banquete de Dios, para que comáis carne de valientes, carne de caballos y de sus jinetes, y carne de toda clase de gente, libres y esclavos, pequeños y grandes" 23 .

En efecto, ello queda demostrado por el fragmento del texto que al pie de la miniatura se expresa de este modo: "Explanatio suprascripte... Et vidi angelum... stant... et clamavit vocem... omnibus avibus que vola[bant]..." Así, aparecen dibujadas dos grandes aves de afilado pico, evidentes rapaces, que miran hacia la derecha donde podemos adivinar a otras dos pues se ven sus alas y una pata, cortados sus cuerpos en el extremo del folio (Figura 2). Su diseño podría recordarnos el dibujo de un águila del folio 18 del manuscrito de Villard de Honnecourt $^{24}$, lo cual coadyuva asimismo la cronología que hemos propuesto en torno a fines del primer tercio del siglo XIII. Por otra parte, al ir esta mutilada viñeta intercalada entre las columnas del texto hacia la mitad del folio, la impresión que recibimos es mixta porque contemplamos ilustración y texto al mismo tiempo, pasando luego de la lectura visual a la lectura textual ya que las columnas del comentario se encuentran al pie de la miniatura, al contrario que en la miniatura

${ }^{21}$ NEUSS, Wilhem: Die Apokalypse des Hl. Johannes in der altspanischen und altchristlichen Bibel-Illustration. 1. Reihe, Bd. 2 u. 3. Münster in Westfalen, 1931, p. 212.

${ }^{22}$ Apocalipsis, 20, 4-6.

${ }^{23}$ Apocalipsis, 19, 17-18.

${ }^{24}$ ERLANDE-BRANDENBURG, Alain; PERNOUD, Régine; GIMPEL, Jean; y BECHMANN, Roland: Villard de Honnecourt, Cuaderno, Siglo XIII. Madrid, 1991, lám. 36 y p. 134. 
completa que atrae nuestra atención al primer golpe de vista porque ocupa algo más de la mitad inferior del folio respecto a las columnas del texto y hace que nos detengamos en su contemplación mientras que si deseamos leer el comentario hemos de pasar al folio verso -lo que no ocurría en la miniatura anterior-, pues en la segunda columna del folio recto tan sólo aparece el texto del pasaje que luego se comenta ${ }^{25}$.

El códice al que perteneció esta miniatura quedaría incluido dentro de la familia II de manuscritos -según la clasificación de Neuss-y dentro de esta familia se entronca con la rama b, relacionándose con el Beato románico de San Andrés de Arroyo (n. a. lat, 2290, Bibliothèque Nationale, París) ${ }^{26}$. Este Beato procedente de un monasterio femenino cisterciense, considerado "el más europeo de todos los Beatos" se debió copiar entre 1210 y 1220, según Yarza ${ }^{27}$. Ahora bien, aun cuando iconográficamente se relacione con este modelo castellano, desde el punto de vista estilístico sugiere también contactos con el arte aragonés pues la imagen principal recuerda la figura del Cristo que aparece en la escena de $\mathrm{La} \mathrm{Ad}$ monición de la sala capitular del monasterio de Sigena (Huesca), fundado en 1188 y consagrada su iglesia en 1258, cuyas pinturas debieron realizarse entre 1200 y $1220^{28}$. Esta relación con las discutidas pinturas de Sigena plantea otra cuestión

${ }^{25}$ CÓMEZ, Rafael: El documento más antiguo..., op. cit., p. 29.

${ }^{26}$ NEUSS, Wilhem: Die Apokalypse des Hl. Joannes, op. cit. p. 212; KLEIN, Peter: "La tradición pictórica de los Beatos", en Actas del Simposio para el estudio de los códices del "Comentario al Apocalipsis" de Beato de Liébana (1976). T. II. Madrid, 1980, pp. 85-115; KLEIN, Peter: "Introduction and Codicological Description", en Beatus de Liébana In Apocalypsin Commentarius. Manchester, the John Rylands University Library, Latin MS 8 (ed. en microfichas en color: Codices illuminati medii aevi, 16). Munich, 1990, p. 37; KLEIN, Peter: Beatus de Liébana. Codex Urgellensis. Comentario a la edición facsímil. Torrejón de Ardoz, 2002, p. 37; YARZA LUACES, Joaquín: Beato de Liébana. Manuscritos iluminados, op. cit., p. 304; WILLIAMS, John: The illustrated Beatus. A Corpus of the illustrations of the Commentary on the Apocalypse. The Twelth and Thirteenth Centuries. Vol. V. Londres, 2003, pp. 48-49; WILLIAMS, John: "Los Beatos de Santo Domingo de Silos, San Pedro de León, fragmento de León y fragmento de Rioseco", en SUÁREZ GONZÁLEZ, Ana: Fragmentos de Beatos, op. cit., pp. 102-117; y WILLIAMS, John: Visions of the End in Medieval Spain. Catalogue of illustrated Beatus Commentaries on the Apocalypse and Study of the Geneva Beatus. Amsterdam, 2017, pp. 67-148.

27 YARZA LUACES, Joaquín: “Manuscritos iluminados en el Císter”, op. cit., p. 404; y YARZA LUACES, Joaquín: Beato de Liébana. Manuscritos iluminados, op. cit., p. 233.

${ }^{28}$ COOK, Walter Spencer y GUDIOL RICART, José: Pintura e imaginería románicas, en Ars Hispaniae. T. VI. $2^{\text {a }}$ ed. Madrid, 1980, pp. 88-92; PACHT, Otto: "A Cycle of English Frescoes in Spain", Burlington Magazine, CIII, 1961, pp. 166-175; AINAUD, Juan: La pintura románica. México, 1967, pp. 34-35; OAKESHOTT, Walter: Sigena. Romanesque Paintings in Spain and the Winchester Bible Artist. Londres, 1972; OAKESHOTT, Walter: The two Winchester Bibles. Oxford, 1981; GARDELLES, Jacques: "La prieuré de Sigena aux XIIème et XIIIème siècles: étude architecturale", Bulletin Monumental, 133-I, 
sobre el Beato mexicano procedente de Medina de Rioseco, dado que este ciclo de pinturas aragonés representa un hito dentro de la corriente bizantinizante europea en torno a 1200, en la que desempeña un importante papel el scriptorium que realiza la Biblia de Winchester, cuyo influjo llegó sin que lo sepamos a ciencia cierta hasta Sigena. La relación de los pintores del monasterio aragonés con los maestros ingleses es evidente y aún más con el último miniaturista que se incorporó a dicho scriptorium hacia 1180, con pleno conocimiento de los mosaicos de Cefalú, Monreale y Palermo. Sin embargo, no se conserva en Inglaterra ninguna pintura mural de la categoría de Sigena que presente influjos de los maestros de Winchester, con los cuales se relaciona también el folio Morgan, que formó parte de la misma Biblia ${ }^{29}$.

Posiblemente se relacione con el ciclo apocalíptico de las pinturas murales de Artaiz en Navarra ${ }^{30}$. Comoquiera que la miniatura del Archivo General de la Nación (México D.F.) presenta el trazo firme y seguro del maestro de Sigena y pudiera relacionarse con el maestro de Artaiz, podemos fecharla, por consiguiente, con seguridad, en la primera mitad del siglo XIII. Finalmente, el único dato seguro acerca de esta interesante miniatura es el lugar desde donde fue enviada a México, o sea, Medina de Rioseco, en la actual provincia de Valladolid.

Según John Williams la ilustración 4852 del Archivo General de la Nación (México), que denomina Los fragmentos de Rioseco, procedentes de Medina de Rioseco, representan los pasajes de El Ángel sobre el Sol (Apocalipsis, 19, 17-18), en su porción más pequeña, y Los Jueces Milenarios (Apocalipsis, 20, 4-6) en el folio completo pertenecientes ambos a un mismo beato realizado en la segunda mitad del siglo XIII, vinculado iconográficamente con el Beato de San Andrés de Arroyo y relacionado estilísticamente con las pinturas murales de Arjona y

1975, pp. 15-28; SICART, Ángel: Las pinturas de Sijena. Madrid, 1992, pp. 4-30; y OCÓN ALONSO, Dulce: "Une salle capitulaire pour une reine: les peintures du chapitre de Sigena", Cahiers de Saint-Michel de Cuxa, 38, 2007, pp. 81-94.

29 YARZA, Joaquín: "Oakeshott, W., Sigena. Romanesque Painting in Spain and the Winchester Bible Artist, Londres, 1972", Archivo Español de Arte, 184, 1973, pp. 454456; YARZA, Joaquín: Arte y arquitectura en España (500-1250). Madrid, 1979, p. 294; YARZA, Joaquín: La Edad Media. Historia del Arte Hispánico II. Madrid, 1980, p. 181; YARZA, Joaquín: "La Miniatura Románica en España. Estado de la cuestión", Anuario del Departamento de Historia y Teoría del Arte, II, 1990, pp. 12-16 y 25; OAKESHOTT, Walter: The two Winchester Bibles, op. cit., pp. 75-82; y PÄCHT, Otto: La miniatura medieval. Una introducción. Madrid, 1987, pp. 35, 77, 135 y ss.

30 AINAUD, Juan: La pintura románica, op. cit., p. 35; LACARRA, María del Carmen: Aportación al estudio de la pintura mural gótica en Navarra. Pamplona, 1974, p. 107; YARZA, Joaquín: Arte y arquitectura en España (500-1250), op. cit., p. 294; YARZA, Joaquín: La Edad Media. Historia del Arte Hispánico II, op. cit., pp. 246-247; y MARTÍNEZ ÁLAVA, Carlos: "Pintura y miniatura", en FERNÁNDEZ-LADREDA, Clara: El arte gótico en Navarra. Pamplona, 2015, pp. 135-138. 
Artáiz en Navarra ${ }^{31}$-como hemos señalado con anterioridad-, en todo lo cual coinciden quienes han estudiado dichos fragmentos ${ }^{32}$. Ahora bien, afirma a continuación: "El monasterio de San Miguel de Medina de Rioseco, única residencia documentada de este fragmento antes de su llegada a Méjico, fue fundado en $1132 "$ "3i. Sin embargo, no conocemos ningún monasterio cisterciense de San Miguel en Medina de Rioseco. Sí existió un pequeño templo románico de una nave con esa advocación en la plaza del mismo nombre, del que según Antón, no ha quedado ninguna piedra y solo el recuerdo ${ }^{34}$, además de un dibujo anterior a su destrucción en 1851, según demuestra Gaya Nuño ${ }^{35}$. Sin embargo, no existen referencias a tal monasterio cisterciense que conozcamos en la historiografía sobre los monasterios del Císter en Castilla durante la Edad Media ${ }^{36}$. El hecho de que Williams los denomine "fragmentos de Rioseco" y no "fragmentos de Medina de Rioseco" induce a la confusión con el monasterio cisterciense de Rioseco, fundado en 1148 y situado al norte de la provincia de $\operatorname{Burgos}^{37}$, aunque evidentemente no deba referirse a ese monasterio burgalés.

No muy lejos de Medina de Rioseco, el monasterio cisterciense de la Santa Espina, fundado en 1147 por doña Sancha, hermana de Alfonso VII, para albergar una espina de la corona de Cristo, regalada por Luis VII de Francia ${ }^{38}$, se

${ }^{31}$ WILLIAMS, John: “Los Beatos de Santo Domingo de Silos...”, op. cit., pp. 115-116.

32 Véase nota 26.

33 WILLIAMS, John: "Los fragmentos de Rioseco", op. cit., p. 116.

${ }_{34}$ ANTÓN Y CASASECA, Francisco: Catálogo monumental de la provincia de Valladolid. T. I. Madrid, 1916, p. 121.

35 GAYA NUÑO, Juan Antonio: La arquitectura española en sus monumentos desaparecidos. Madrid, 1961, p. 147.

${ }^{36}$ ANTÓN, Francisco: Monasterios medievales en la provincia de Valladolid. $2^{\mathrm{a}}$ ed. Valladolid, 1942; ÁLVAREZ PALENZUELA, Vicente Ángel: Monasterios cistercienses en Castilla (siglos XII-XIII). Valladolid, 1978; PÉREZ-EMBID WAMBA, Francisco Javier: El Císter en Castilla y León: monacato y dominios rurales (siglos XII-XV). Valladolid, 1986; PARRADO DEL OLMO, Jesús María: Catálogo Monumental de la provincia de Valladolid. Tomo XVI. Antiguo partido judicial de Medina de Rioseco. Valladolid, 2002; y GARCÍA FLORES, Antonio: Arquitectura de la Orden del Císter en la provincia de Valladolid (1147-1515). Valladolid, 2010.

37 ÁLVAREZ PALENZUELA, Vicente Ángel: Monasterios cistercienses en Castilla, op. cit., pp. 131-132; y PÉREZ-EMBID WAMBA, Javier: El Císter en Castilla y León, op. cit., pp. 271-274.

${ }_{38}$ ANTÓN, Francisco: Monasterios medievales de la provincia de Valladolid, op. cit., pp. 115 y ss.; PARRADO DEL OLMO, Jesús María: Catálogo Monumental de la provincia 
decía haber intervenido en su edificación Nivardo, posiblemente el hermano de San Bernardo de Claraval.

Dentro del conjunto monacal destaca la iglesia cuya construcción, según Torres Balbás ${ }^{39}$, no debe ser anterior al segundo cuarto del siglo XIII como demuestran sus pilares semejantes a los de Santa María de Valdediós, que datan de 1218, obra de un buen maestro que la dejó inacabada pues estaba edificándose todavía en 1275 y una década más tarde seguía sin terminar hasta que don Juan Alonso de Alburquerque terminó las naves colaterales del templo, las tres capillas que faltaban y lo que restaba del monasterio en torno al claustro, quedando dicha casa nobiliaria como patronos del monasterio, donde tendrían sepultura junto con sus esposas así como también doña Leonor, hija de Juan II de Castilla. Ciertamente, el edificio sufrió construcciones y reconstrucciones a partir del siglo XV cuando se levanta la capilla de los Vega, señores de Grajal, mientras que entre 1546 y 1558 se reedificaba la capilla mayor y el cimborrio, colocándose los sepulcros de los Alburquerque en tiempos del abad fray Lorenzo de Horozco y, más tarde, en 1635 se abría en el lado de la epístola la capilla de la Santa Espina con diseño de Francisco de Praves ${ }^{40}$. No cabe duda de que la obra fue lenta en función de los apuros económicos del monasterio ${ }^{41}$, de tal manera que el mayor empuje constructivo se corresponde a su momento de expansión y prosperidad (1147- c. 1225), según García Flores, cuando la iglesia y lo fundamental del monasterio alcanzan la forma perfecta de cenobio cisterciense ya que su planta responde al "plan bernardin" realizado por Nivardo, encargado de "elegir el sitio y dar la traza" del nuevo monasterio "traçandole... conforme al de Claraval"42 (Figura 3), como atestiguan distintos documentos.

de Valladolid, op. cit. p. 52; y GARCÍA FLORES, Antonio: Arquitectura de la Orden del Císter en la provincia de Valladolid, op. cit., pp. 93-94.

${ }^{39}$ TORRES BALBÁS, Leopoldo: Arquitectura gótica, en Ars Hispaniae. T. VII. Madrid, 1952, pp. 104-107.

${ }^{40}$ PARRADO DEL OLMO, Jesús María: Catálogo Monumental de la provincia de Valladolid, op. cit., pp. 52 y 54.

${ }^{41}$ ANTÓN, Francisco: Monasterios medievales en la provincia de Valladolid, op. cit., p. 145 .

${ }^{42}$ GARCÍA FLORES, Antonio: Arquitectura de la Orden del Císter en la provincia de Valladolid, op. cit., pp. 100 y 108-109. El origen de la fundación en el viaje de peregrinación de doña Sancha a Tierra Santa, pasando por Roma donde Inocencio II le da un dedo de San Pedro y un fragmento del Lignum Crucis, y luego por Francia, visitando a Bernardo de Claraval que envía a su hermano para la nueva fundación y, finalmente, el regalo de una espina de la corona de Cristo, guardada en la abadía de Saint Denis, por Luis VII y su sobrina Constanza, es una tradición mantenida hasta la modernidad, aunque Nivardo bien pudo ser cualquier hermano cisterciense que no fuera físicamente hermano del santo. Véase GARCÍA FLORES, Antonio: Arquitectura de la Orden del Císter en la provincia de Valladolid, op. cit., pp. 93-94. 
Dentro de la panda del claustro que linda y comunica con la iglesia cuyo proceso constructivo ha sido estudiado exhaustivamente por el autor antes mencionado, se encuentran el locutorio, el calefactorio y un largo pasillo hacia la huerta, destacando la hermosa sala capitular contigua a un espacio compartimentado que ocupan dos estancias: la sacristía en el sector oriental y el armarium claustri en el occidental (Figura 4). Lo más notable es que el armarium no consiste en un nicho excavado en el muro como ocurre tantas veces sino en una sala a continuación de la sacristía, comunicada con ella y con acceso directo desde el claustro $^{43}$. Este armarium de La Espina ha llamado la atención de todos quienes se han ocupado del monasterio desde Francisco Antón quien lo considera "uno de los ejemplares más interesantes que subsisten de tales dependencias" de comienzos del siglo XIII, indicando que además de biblioteca sería acaso archivo ${ }^{44}$. El hecho de la amplia estructura del armarium, consistente en un espacio relativamente grande comparado con el de otros monasterios cistercienses, nos habla de la importancia del scriptorium que albergara el monasterio de La Espina ya que, generalmente, la presencia de una biblioteca monacal es indicio de la existencia de un scriptorium próximo.

Aunque no tengamos noticias de dicho scriptorium ni tampoco la certeza de que allí se iluminara algún códice ni siquiera nuestro beato, poseemos, en cambio, el hecho arquitectónico de una de las bibliotecas monásticas más importantes de la Península Ibérica. No obstante, Ambrosio de Morales, en su interesante viaje por las catedrales y monasterios del noroeste de España, al llegar al de la Espina encontró una "Exposición del Apocalypsi, sine nomine Auctoris: podría ser la de Beato, de quien he dicho en otras librerías" 45 .

La escueta cita es importante para que pensáramos en la posibilidad de que se tratara, tal vez, del beato mexicano que ocupa nuestra atención, dada también la proximidad del monasterio de La Espina -unos veinte kilómetros aproximadamente- con la localidad de Medina de Rioseco ${ }^{46}$. Sin embargo, Ana Suárez de quien hemos tomado la cita-, aun reconociendo la existencia allí de un taller

${ }^{43}$ GARCÍA FLORES, Antonio: Arquitectura de la Orden del Císter en la provincia de Valladolid, op. cit., pp. 139-143.

${ }^{44}$ ANTÓN, Francisco: Monasterios medievales en la provincia de Valladolid, op. cit., p. 147. Otros destacan la amplia estructura de la librería o armariolum semejante a una habitación. Cf. PÉREZ-EMBID WAMBA, Javier: El Císter en Castilla y León, op. cit., p. 301; y PARRADO DEL OLMO, Jesús María: Catálogo Monumental de la provincia de Valladolid, op. cit., pp. 54-55.

${ }^{45}$ AMBROSIO DE MORALES: Viage de A... de M... por orden del rey $D$. Phelipe II a los reynos de León y Galicia, y principado de Asturias para reconocer las reliquias de Santos, sepulcros reales, y libros manuscritos de las Catedrales, y Monasterios. Madrid, 1765, p. 190, Apud SUÁREZ GONZÁLEZ, Ana: “Los otros beatos”, op. cit., p. 78, nota 363.

${ }^{46}$ El dominio y las posesiones del monasterio de La Espina llegaban hasta Medina de Rioseco. Véase ÁLVAREZ PALENZUELA, Vicente Ángel: Monasterios cistercienses en 
bibliográfico, no la considera de interés porque según la descripción de Ambrosio de Morales "el manuscrito no era demasiado antiguo" y "tampoco sobresalía por su aspecto externo" 47 , aunque el hecho concreto es que vio una exposición del Apocalipsis que "podría ser la de Beato", la cual había ya visto en otras bibliotecas.

Empero, en primer lugar, no sabemos por qué razón no pareciera demasiado antiguo y, segundo, que no sobresaliera por su aspecto bien pudiera ser porque no le llamara la atención por el hecho de que carecieran de color sus miniaturas. Además, por otra parte, no sabemos tampoco por qué tuvo que estar el códice ya desmembrado como "pergamino viejo"48 cuando tuvo lugar el viaje de Ambrosio de Morales en 1572. Si leemos detenidamente la carta de Gregorio de Quintana a su hermano en 1575 antes de que partiera hacia América, podemos comprobar que la principal preocupación de nuestro personaje era "que su merced me haga merced de negociar cómo se me saque un traslado de la ejecutoria, digo un original autorizado, por ante los señores alcalde de hijosdalgo, de manera que sea válido" ${ }^{49}$, y que termina recordándole que no olvide sacar la ejecutoria con toda diligencia. Esto nos demuestra que desde 1559 no había salido todavía de Medina de Rioseco el expediente de limpieza de sangre que solicitaba con vehemencia Gregorio de Quintana. Por lo tanto, hasta 1576 no le llevaría su hermano la genealogía y limpieza de sangre a Pánuco de Zacatecas y, consecuentemente, dicho expediente no sería encuadernado antes de 1572, por lo cual cabe la posibilidad de que el Beato que viera Ambrosio de Morales en la biblioteca del monasterio de La Espina fuera el manuscrito que nos ocupa.

Que el monasterio fuera saqueado a comienzos del siglo XIV o sufriera un incendio en 1731 "que destruyó casi por completo su biblioteca y archivo" ${ }^{50}$ nos ha privado de conocer la riqueza de sus fondos y no es óbice para que el comentario al Apocalipsis de Beato de Liébana visto por Ambrosio de Morales en la librería del monasterio de La Espina fuese, posiblemente, el que, una vez desmembrado, llegara hasta México en uno de sus folios sirviendo de cubierta al expediente de limpieza de sangre de Gregorio de Quintana.

Sin embargo, la opinión de Ana Suárez es contraria a la de los historiadores del arte respecto a la cronología, llevándola hasta el último tercio del siglo XIII por la escritura y configuración de página, indicando que la miniatura podría ser

Castilla, op. cit., pp. 91-97 y 168; y PÉREZ-EMBID WAMBA, Javier: El Císter en Castilla y León, op. cit., pp. 271, 276, y 771.

${ }^{47}$ SUÁREZ GONZÁLEZ, Ana: "Los otros beatos", op. cit., p. 79.

48 Ibidem.

${ }^{49}$ OTTE, Enrique: Cartas privadas de emigrantes a Indias (1540-1616). Sevilla, 1988, p. 214.

${ }^{50}$ RODRÍGUEZ DE DIEGO, José Luis: El Tumbo del monasterio cisterciense de La Espina. Valladolid, 1982, pp. 9 y 21. 
"imitativa y retardataria", antigua ya cuando se elaborara el libro ${ }^{51}$. Difícilmente podríamos considerar esta miniatura como imitativa y retardataria si tenemos en cuenta la indiscutible calidad del dibujo y su relación con el Beato románico de San Andrés de Arroyo del primer tercio del siglo XIII, en el cual se inspira. Por otra parte, estilísticamente, se relaciona con las pinturas de Artaiz en Navarra ${ }^{52}$, como señalamos con anterioridad, por lo cual habría que adscribirla partiendo del movimiento de gran transformación artística que tiene lugar en torno al año $1200^{53}$. No obstante, no es la primera vez que se le da una cronología más tardía que la nuestra. Serafín Moralejo le atribuía la misma datación que le había dado a la miniatura de Fernando III sedente del Tumbo A de la catedral de Santiago de Compostela, es decir, "circa 1255 o algo posterior" ${ }^{4}$. Ahora bien, si comparamos dicha miniatura de Fernando III -que ya clasificó Domínguez Bordona dentro del estilo gótico lineal ${ }^{55}$ - con la del Beato mexicano en lo único que coinciden es en que ambas figuras están sentadas pues la delicadeza y finura del dibujo del Beato más próxima al estilo 1200 contrasta con el aspecto áspero y brusco de la miniatura compostelana. De cualquier manera, es bien sabido que el estilo gótico lineal abarca el arco cronológico del reinado de Fernando III de Castilla que murió en $1252^{56}$. Y en algo en lo que no duda Ana Suárez ${ }^{57}$ es en la adscripción del Beato mexicano a la rama II b y su relación con el Beato de San Andrés de Arroyo, en lo que están de acuerdo todos los historiadores del arte.

Opinamos que la miniatura 4852 del Archivo General de la Nación de México copió el Beato de San Andrés de Arroyo durante el reinado de Fernando III de Castilla y León en un scriptorium indeterminado que podría ser el del monasterio de La Santa Espina, dado su amplio dominio y proximidad a Medina de Rioseco donde el códice fue desmembrado como "pergamino viejo" en el siglo XVI, habida cuenta su magnífica librería cuyo significativo armarium es buen indicio de un importante scriptorium. Sabemos que el Beato de San Andrés de Arroyo estuvo en aquel monasterio cisterciense femenino pero no se ilustró alli ${ }^{58}$ y que

${ }^{51}$ SUÁREZ GONZÁLEZ, Ana: "Los otros beatos", op. cit., p. 80.

52 Véase nota 30.

53 Véanse notas 17, 18, 19 y 20.

${ }^{54}$ MORALEJO ÁLVAREZ, Serafín: "El mapa de la diáspora apostólica en San Pedro de Rocas: notas para su interpretación y filiación en la tradición cartográfica de los Beatos", Compostelanum, XXXI, 3-4, 1986 nota 35, pp. 330-331; y MORALEJO ÁLVAREZ, Serafín: "La miniatura en los Tumbos A y B", en DÍAZ Y DÍAZ, M. C. et alii: Los Tumbos de Compostela. Madrid, 1985, pp. 43-64, láms. XXV y XXVII.

${ }_{55}$ DOMÍNGUEZ BORDONA, Jesús: Miniatura, en Ars Hispaniae. T. XVIII. Madrid, 1962, pp. 130-132, fig. 155.

${ }^{56}$ Véase nota 17.

${ }^{57}$ SUÁREZ GONZÁLEZ, Ana: "Los otros beatos”, op. cit., p. 82.

${ }^{58}$ YARZA LUACES, Joaquín: "La miniatura románica en España. Estado de la cuestión”, op. cit., p. 17. 
se relaciona también con el Beato de Las Huelgas. Dentro de la última producción pictórica de estos manuscritos iluminados, el Beato de Las Huelgas de 1220, estuvo antes en el monasterio de San Andrés de Arroyo pero se desconoce el scriptorium en el que fuera copiado ${ }^{59}$. Si esto es así y resulta imposible determinar con seguridad la procedencia de estos manuscritos, ¿podemos negar la posibilidad de que sea el monasterio de La Santa Espina donde hubiese sido copiado el último códice de la tradición pictórica de los Beatos uno de cuyos folios descuartizados (fragmento 4852, AGN, México) como cubierta de un expediente de limpieza de sangre llegara hasta las minas de Pánuco en las Zacatecas mexicanas?

Fecha de recepción: 30 de octubre de 2017

Fecha de aceptación: 30 de enero de 2018

${ }^{59}$ WILLIAMS, John: Visions of the End in Medieval Spain, op. cit., p. 65. 


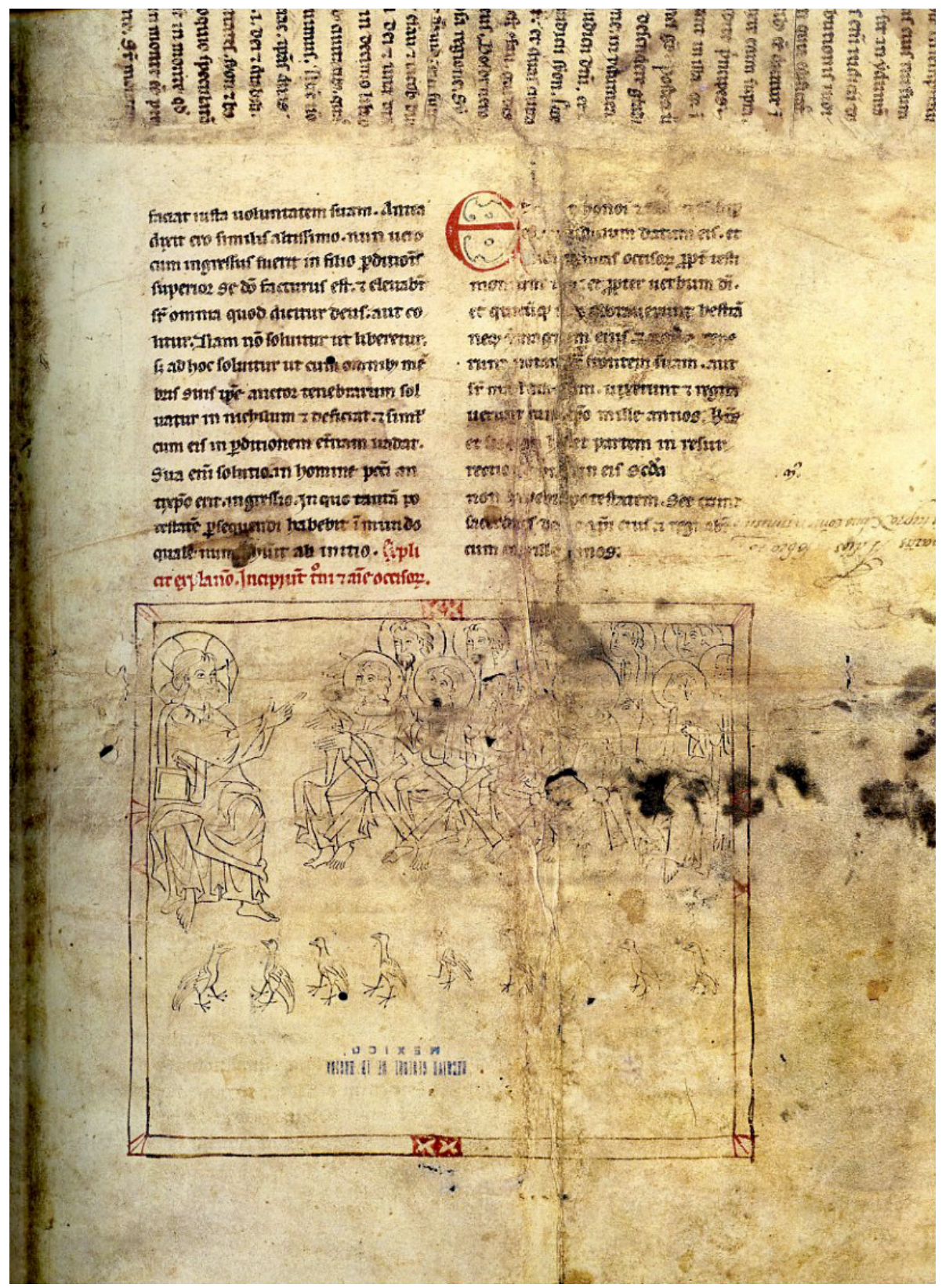

Figura 1. Ilustración 4852, f. r. Archivo General de la Nación, México. 


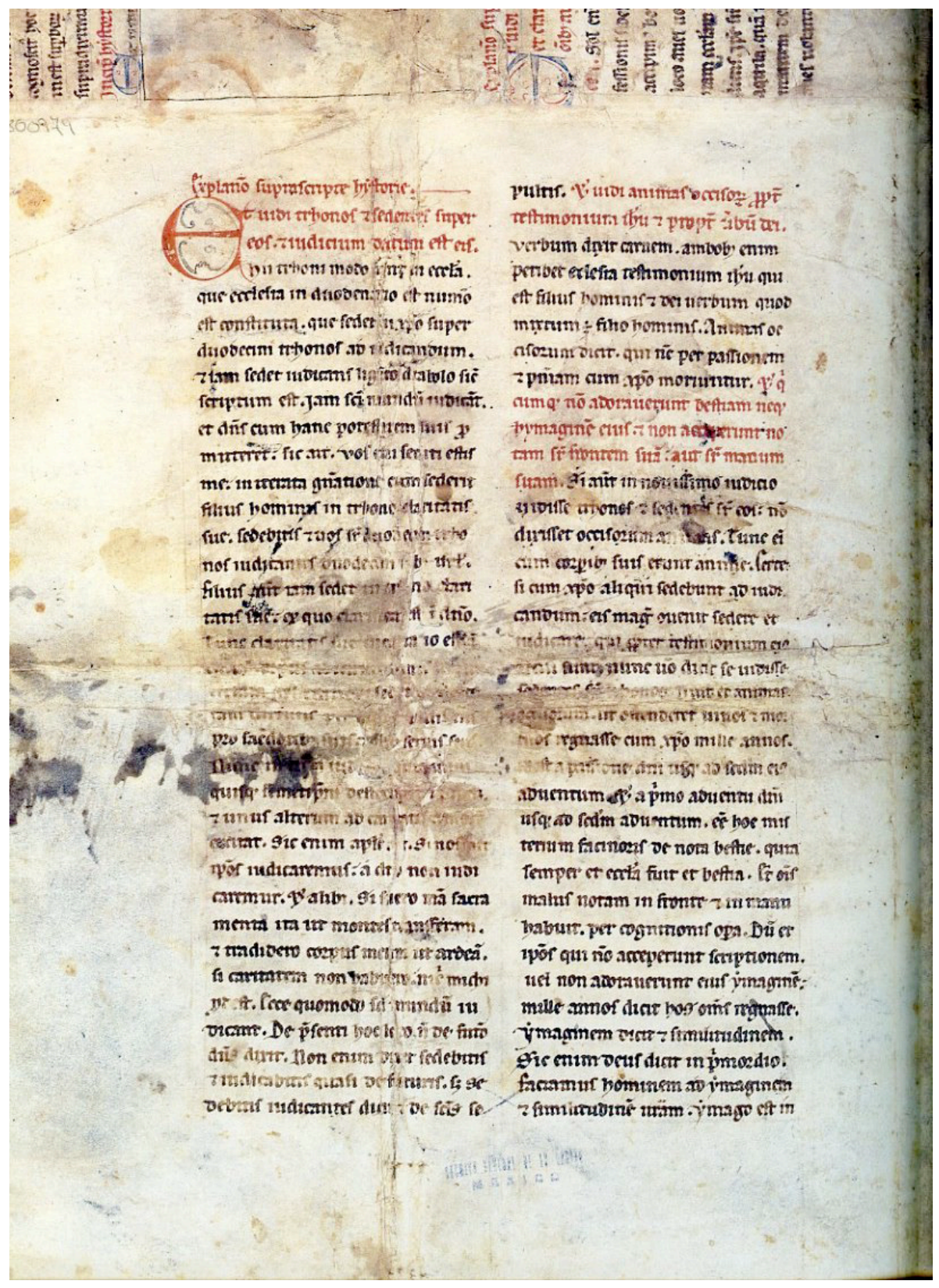

Figura 2. Ilustración 4852, f. v. Archivo General de la Nación, México. 


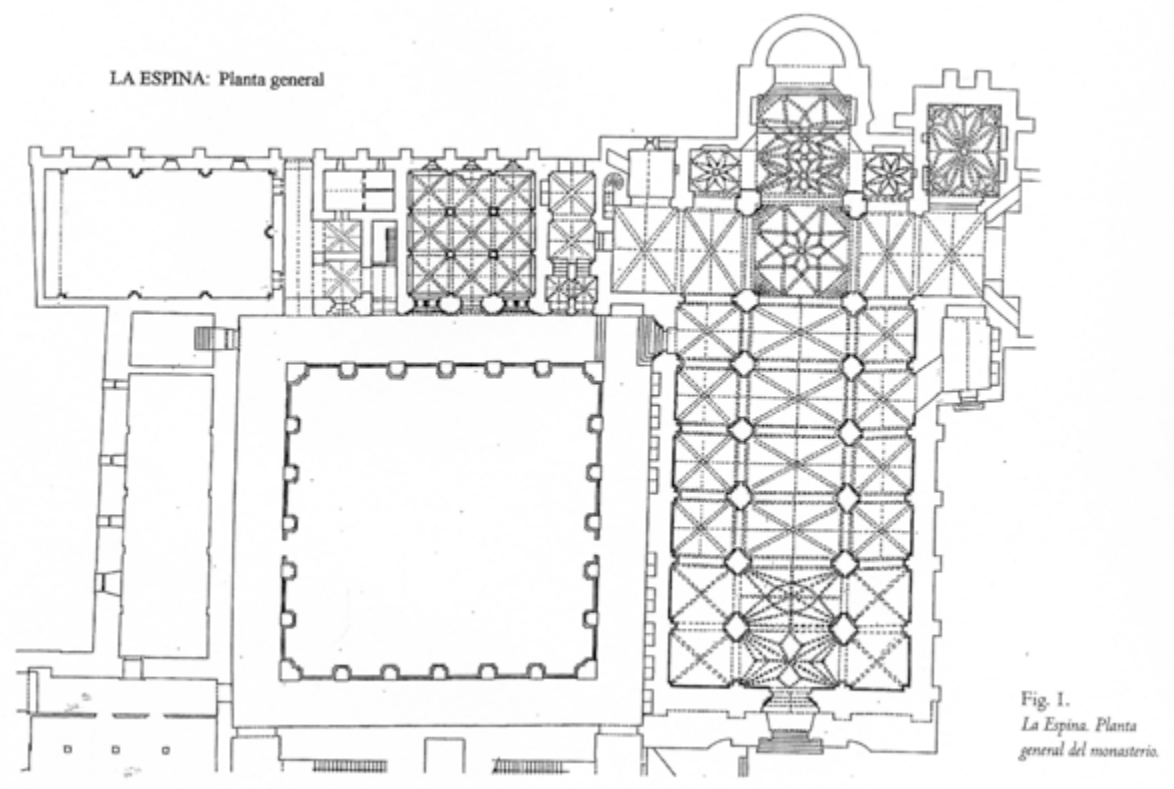

Figura 3. Planta, monasterio de la Santa Espina (Valladolid). Dibujo: Antonio García Flores. 


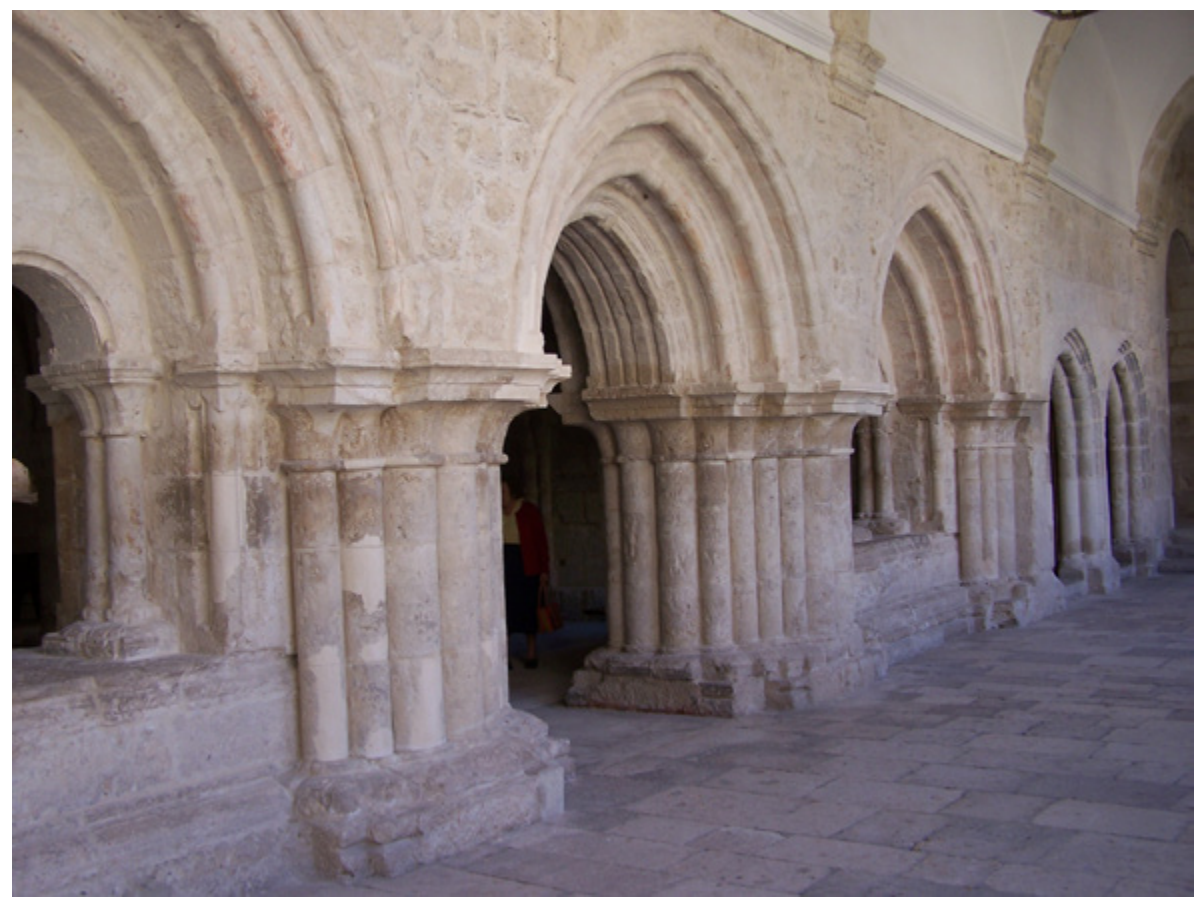

Figura 4. Sala capitular, al fondo puerta del armarium, monasterio de la Santa Espina (Valladolid). Foto: Rafael Cómez Ramos. 